\title{
Application on Situational Teaching Model in Primary School Chinese Teaching
}

\author{
Ye Wang \\ Normal College, Shenyang University, Shenyang, 110044, China \\ 1050159072@qq.com
}

\begin{abstract}
Keywords: situational teaching model; theoretical basis; primary school Chinese teaching; existing problems; application strategies
\end{abstract}

\begin{abstract}
Primary school Chinese teaching plays an important role in cultivating students' emotional attitude, outlook on life and values. Application of situational teaching model, deepen the students' understanding of the teaching materials, in the context of thinking and rational analysis, so that students are more likely to accept new knowledge. In this paper, according to the existing problems in primary school Chinese teaching, it puts forward the application strategy of situational teaching mode in primary school Chinese teaching by using the related theory of situational teaching method, so as to stimulate students' interest and improve the effect of primary school Chinese teaching. Specific strategies include: the timely creation of the situation, according to the focus of teaching materials and difficult scenarios, through the creation of the situation to obtain language, pay attention to the authenticity of the situation, to ensure a good atmosphere of exchanges and cooperation, the use of information technology to create situations, mobilize a variety of sensory experience.
\end{abstract}

\section{Introduction}

Chinese is an important discipline of humanities and social sciences, and it is the Chinese language tool for people to exchange ideas, is the basis for learning other disciplines and science. Chinese is both a practical tool for language norms, but also culture and art, but also the accumulation and development of spiritual wealth. Chinese is an important discipline at any time. In the context of the new curriculum reform, the importance of Chinese disciplines is more prominent. Chinese teaching should not only cultivate students' "listening, speaking, reading and writing" ability, but also imparts language and culture knowledge. Students have a certain Chinese knowledge and skills, to learn other disciplines and to lay a good foundation for the community.

Chinese is the most important basic disciplines, the importance of primary school Chinese teaching is reflected in the following four aspects [1, 2]: First, cultivate students' cultural heritage. China is a long history of ancient civilization, with the glorious history and culture of five thousand years. Primary school is the enlightenment stage of learning, is to accept the new knowledge of the fastest stage, Chinese knowledge for future learning to lay a solid foundation, for the cultivation of students' cultural heritage is very important. Second, lay the foundation for student development. Chinese is a discipline that needs to accumulate slowly. Primary school is the initial stage of learning, pay attention to Chinese learning in primary school stage, and guide students from the basic listening and speaking to reading and writing, to reading and communication, the cultivation of student literacy and learning development has a very important significance. Third, raise the level of writing. Writing is the embodiment of the comprehensive Chinese quality of students, and good and solid writing is based on the basic conditions of society. Improve the level of writing requires a good language foundation, but also need long-term accumulation. Chinese language learning will involve a lot of literary works and excellent literary works, students in the process of understanding and learning, will be in the mind to accumulate a lot of material, to provide inspiration for writing, effectively improves the writing level. Fourth, lay the foundation for other disciplines. Professor Su Buqing, a famous educator, said: "Mathematics is the basis for learning the natural sciences, and the Chinese is the basis of this foundation." It can be seen through the Chinese teaching to develop 
students' reading ability, thinking ability and understanding ability. Only to learn the language, in order to better learn mathematics and foreign languages and other courses, have an irreplaceable role in learning and living for the students.

Primary school students' nature fun and active, attention is easy to disperse, self-control is not strong, and have a strong curiosity about new things. In order to enable students to maintain interest in learning Chinese, if the teaching in a single form, the students will just ignite the spark of interest extinguished.To guide students to change the form of learning, and constantly meet the curiosity of students, is to promote students to learn an important measure. If teachers in the teaching to seize the psychological characteristics of children, and transform the situation, to create a relaxed and happy, harmonious and funny classroom atmosphere, it will stimulate students' desire for knowledge, and gradually lead to and strengthen students' interest in learning Chinese [3]. In this paper, according to the existing problems of primary school Chinese teaching, this paper studies the application of situational teaching mode in primary school Chinese teaching by using the related theories of situational teaching method. In order to improve the teaching level of primary school Chinese, this paper comprehensively improves the quality service of students.

\section{Situational Teaching Method and Its Theoretical Basis}

Situational teaching is the teaching process, according to the basic principle of education and psychology, according to the student's age and cognitive characteristics, between teachers and students, through establishing a cognitive object and cognitive emotional atmosphere, the creation of appropriate learning environment, so that the teaching in a positive emotional and optimal environment to carry out, participate in cognitive activities let the learner's emotional activities, in order to activate the learner's situational thinking, so a teaching activity in situational thinking to acquire knowledge, cultivate ability and develop intelligence. Situational teaching model is different from pedagogy and is different from teaching theory. It is only based on the principles of pedagogy, epistemology, psychology and pedagogy, and fully develops non-intellectual factors in cognitive activities so as to realize the basic teaching mode of pleasant teaching.

Situational teaching method has three characteristics: First, the specificity, teachers according to the specific content of teaching, combined with the specific life scenes, the use of this stage of the classroom for students to create a specific, image and intuitive learning environment; Second, the image, teachers use information technology, audio equipment and pictures and other external means to create classroom situations, so that students immersive, and truly feel the existence of the situation, through a number of dimensions to observe and understand the learning object; Third, the fun, interest is the best teacher, through the creation of the situation, students feel the characteristics of learning objects, which continue to deep interest in the study of learning object.

The research and application of situational teaching method, based on the following theoretical basis: First, the theory of constructivism. Constructivism argues that learning is a process of constructing meaning in a given context, with the help of others, through intercultural collaboration, "context", "collaboration", "conversation" and "meaning construction" are the four main factors in learning environments. In the constructivist learning environment, the teaching design should not only consider the teaching goal analysis, but also consider the creation of the situation conducive to the meaning construction of students, and the context of creation as one of the most important content of teaching design. Second, situational learning theory. Situational learning theory holds that learning is not only the psychological process of individual meaning construction, but also a social, practical, participatory process with differentiated resources. Situational learning emphasizes two principles of learning: first, presenting the knowledge in the practical application of knowledge in the real situation, to combine theory and application, so that learners like experts to think and practice; second, through social interaction and collaboration to carry out learn. Third, the "midwifery" principle [4]. Ancient Greek philosophers put forward the theory of "midwifery", "I do not teach others by knowledge, but do the midwife to produce knowledge." The midwifery stage is mainly inspired to guide students, so that students can draw conclusions through thinking. Inductive definition stage, so that students gradually grasp the clear definition and concept. By stimulating 
learning motivation, guide students to carry out in-depth thinking and exploration for new problems, thereby improving learning efficiency.

\section{Existing Problems on Primary School Chinese Teaching}

Chinese teaching not only instills basic knowledge and skills, but also the students' mind and personality to shape. At present, the teaching of primary school Chinese has made some achievements, but there are still many problems, which affect the improvement of teaching level and the cultivation of students' ability. To sum up, the main problems are as follows:

(1) Personality is released, lack of norms of behavior. Cultivating the child's personality, can improve the students' independent thinking and problem-solving ability, but also can release the child's nature. In the classroom, teachers attach importance to the interaction between students; classroom atmosphere can be active to promote students' interest and motivation. However, the self-control ability of primary school students relative to the poor, so that students are free to speak unconstrained, prone to poor classroom control, resulting in decreased teaching efficiency.

(2) teacher-led classroom, students in a passive acceptance. Primary school Chinese teacher plays a leading role in the classroom, in order to put the textbook knowledge to the students, blindly let students remember the focus, repeated reading, copying and recitation, classroom atmosphere is boring, resulting in students will only passively listen, mechanical reading and recitation, the student's personal opinion has no chance to express it, ignoring the student's dominant position, strangling the student's desire for knowledge and innovation.

(3) Deviated from the characteristics of Chinese courses, ignoring the basic skills of language training. Chinese language curriculum is characterized by the importance of nurturing infection, pay attention to the value of teaching content orientation, respect for the unique experience of students, so that students more contact with language materials, in practice to master the law. Many teachers do not attach importance to literacy and writing teaching, training is not in place, students literacy is not enough, writing is not standardized; reading teaching impermeable writing factors, reading and writing out of touch; basic skills training machinery monotonous, written practice design obsolete.

(4) Attention to local knowledge, despise the overall perception [5]. The ultimate goal of primary school Chinese education is to enable students to learn knowledge at the same time, have a noble moral sentiment, healthy aesthetic taste, the correct values and positive attitude towards life. Some primary school Chinese teaching has raised the students' understanding of the words, but did not teach the students the specific meaning of the words. Some teachers only from the local part of the selected fragments, directly out of the environment or context given by the text, despise the overall perception of the article.

(5) Only emphasizes the completion of teaching tasks, ignoring the reading and accumulation. Classroom students have too little time to read book, teachers will spend a lot of time in teaching materials. The reading classroom is full of words and sentences training and chapter analysis, students reading and exercise too little. Classroom teaching teachers take up too much time, students learn less time. The memory and recitation of excellent language materials have not been paid enough attention, affecting students' reading ability and self-learning ability.

(6) Teaching method is a single way, the lack of innovative ideas. In many primary school Chinese classes, Chinese teachers usually use only one language book, a lesson plan, a chalk and a mouth, and can complete the teaching task, the day after day teaching methods, so that the original lively and vivid language classroom was boring, teachers just to complete the teaching task, the students just to cope with the examination, the loss of the most basic meaning of learning, so that students from childhood to have emotional weariness, is bound to affect the future stud and development.

(7) The use of traditional teaching model can not stimulate student interest. Some teachers in order to complete the teaching tasks, the use of traditional coping test mode of teaching, the teaching process is to let students understand the words, sort out the article paragraph level, to find a beautiful paragraph sentence analysis, general article center thinking. Interest is the best teacher, if you do not think about what the article, what is the meaning of the article, what learned from the 
article, but boring repetitive learning, can not stimulate students' interest and motivation, teaching will lose its meaning.

(8) Textbook knowledge can not be integrated into life, students difficult to understand. The primary school stage is a new stage of learning from scratch, the knowledge storage of primary school students is less, life experience is not rich, understanding ability is limited, and acceptance of knowledge is a new challenge for students. Many language teachers did not pay attention to the characteristics of primary school students, but in accordance with the knowledge of the textbook to teach, not the textbook knowledge into the life well, students difficult to understand and master all the knowledge.

\section{Application Strategies on Situational Teaching Model in Primary School Chinese Teaching}

Situational teaching is an important way to improve students' Chinese learning level, but also has its two sides. If you use improperly, some problems will affect the teaching effect. Aiming at the existing problems of Chinese teaching in primary schools, the following application strategies are put forward:

(1) Timely creation of the situation, to stimulate student emotions [6]. Educator J.A.Comenius said: "all knowledge begins with the senses." Therefore, the Chinese teachers are full of passion to create the appropriate emotional teaching, students can enjoy the interest of learning, so that students in the best emotional state. Students feel happy, focused. Teachers and students can effectively carry out intellectual activities and emotional communication. Therefore, in the teaching should pay attention to the timely establishment of a variety of situations, stimulate students' emotions, create a good "emotional field", guide students into the best learning situation, optimize teaching effect.

(2) According to the teaching materials focus and difficult to design the situation. Pay attention to three aspects in the specific application: First, situational introduction, to seize the import links, quickly attract students attention, induced interest in learning, improve the effect of class lessons. The usual methods of introduction are: illustrations, couplets, riddles, stories, movies, objects, music and contrast. Second, the suspect situation, classroom counseling is an effective way to open the students mind and stimulate motivation. "Suspected" set up well, set fine, set up clever, can stimulate student interest, activate student thinking. Third, the game situation, the game is the child willing to do the activities. Teachers to identify the combination of the game and teaching content, so that students forget their own learning, in this unconscious or subconsciously ecstasy into the state, improve students' memory and ability to understand.

(3) To acquire the sense of language by creating situations. Primary school students' abstract thinking ability is weak, understanding things more intuitive, to comprehend the expression of language connotation, should fully mobilize their image thinking. Through the "path" of the image thinking, the language described the situation "converted" into vivid "image" material, so that students in the immersive experience in cultivating emotions, perception of the text situations, access to a rich sense of language. Creating a situation is a catalyst that encourages students to comprehend. can create a corresponding situation with a variety of teaching methods: life scenes, vivid images, musical melodies and physical demonstrations, and so on, which can stimulate the emotional experience of students, so that the language becomes a distinctive image printed in the mind, make students feel personally on the scene in language, get the language training in the subtle.

(4) Focus on the authenticity of the situation, to ensure good exchange and cooperation atmosphere. The more realistic the situation is, the more reliable the knowledge of learner's construction is, and the easier it is to use it in the real situation. "Real situation" has the original real and artificial real points. According to the original real to build artificial real, well-designed teaching situation, this is one of the important contents of teaching design [7]. In the process of teaching Chinese, must interact with students to create situations that correspond to the teaching content, and promote the exchange and cooperation between students and between students and teachers. Classroom teaching to improve the students' initiative, the learning atmosphere is more 
intense. To form the mutual learning, competition, cooperation and solidarity between students by creating the situation,

(5) The use of information technology to create situations, to mobilize a variety of sensory experience. Multimedia and network as the core of modern information technology, so that knowledge is no longer a single form of text to pass, but into the sound, pictures and images and other media hypertext, changing the way of thinking and learning. From the primary school students' psychological and thinking characteristics, intuitive and image teaching is easy to attract interest and attract attention. In teaching, colorful and vivid multimedia courseware, often attract students' attention. And describes the text of the beautiful scenery, can use pictures, images and music rendering means to create the situation, the use of intuitive image effects to attract students enter the situation. There are many ways to create a situation, the use of information technology to create the situation has a unique advantage, can optimize the classroom introduction, optimize the content explanation, and optimize the feedback evaluation.

\section{Conclusion}

Primary school Chinese teaching plays an important role in cultivating students' emotional attitude, outlook on life and values. Primary school Chinese classroom teaching, should be fully believe that students, and rely on students and service students, and to students as the main, is a relaxed and effective classroom. In addition to the use of the previously proposed strategy, or pay attention to: the introduction of the situation, in the fun of inquiry to induce motivation; through the situation, in the aesthetic pleasure to rich feelings; into the situation, in the fun of experience to cultivate emotions; optimize the situation, increase strength in fun; create a situation, in the creation of fun to show personality; broaden the situation, in the fun of understanding around the world to broaden their horizons. Teachers should be familiar with the teaching model of situational education, skilled and appropriate use of various situations to create methods to stimulate students' interest in learning, cultivate learning ability, and improve the level of intellectuals, to meet the needs of students' healthy and comprehensive development

\section{References}

[1] S. Z. Luo, "On the difficulties and countermeasures of Chinese teaching in primary schools," New campus, vol. 17, no. 3, pp. 68-68, 2016.

[2] F. Fu, "On the importance of Chinese teaching in primary school," Read, write and calculate: education teaching research, vol. 31, no. 43, pp. 257-257, 2015.

[3] Baidu Wenku, "I have seen on situational teaching for primary Chinese," https://wenku.baidu.com/view/018d1d4ff7ec4afe04a1df48.html, 2017-3-11.

[4] Y. B. Ou, "On situational teaching method and its theoretical basis," Economic management, vol. 13, no. 9, pp. 52-52, 2016.

[5] X. L. Zhu, Y. S. Zhang, "Reflections on the characteristics of Chinese teaching in primary schools," Education for Chinese After-school, vol. 8, no. 32, pp. 169-169, 2013.

[6] Graduation paper net, "On the importance of Chinese education in primary school," http://biyelunwen.yjbys.com/fanwen/jiaoxue/422499.html, 2017-3-11.

[7] H. B. Li, "Application of situational teaching method in College Chinese teaching in science and Engineering Colleges," Data of Culture and Education, vol. 36, no. 28, pp. 197-198, 2009. 